\title{
The Investigation of the Depressor Additives Application Efficiency for Asphaltene-Resin-Paraffin Deposits Inhibition and Stripping in Petroleum Storage Tanks
}

\author{
ARLAN ZAINUTALLAEVICH ABILMAGZHANOV*, NIKOLAY SERGEEVICH IVANOV, \\ SERIK SAMSALIEVICH KOZHABEKOV, ERLAN NURZHANULY ABDIKALYKOV, ULDANA \\ ORMANKYZY KYDYRBAYEVA and AIZHAN ERKINBEKKYZY NURTAZINA
}

Institute of Fuel, Catalysis and Electrochemistry named after D.V. Sokolskiy, Almaty, Republic of Kazakhstan

*Corresponding author E-mail: a.abilmagzhanov@ifce.kz

http://dx.doi.org/10.13005/ojc/350229

(Received: November 06, 2018; Accepted: March 15, 2019)

\begin{abstract}
Possibility of heated petroleum application with various additives addition as solvents for asphaltene-resin-paraffin deposits was analyzed. An object of this investigation was chosen petroleum selected from tank farm of the Kazakhstan oil refinery and samples of bottom sediments (ARPD) formed during storage in tanks. Deposits type in line with ARPD classification was identified. Additives impact on petroleum capacity in relation to ARPD was investigated. The most effective additives to inhibiting and removing bottom settlings formed in petroleum storage tanks were determined.
\end{abstract}

Keywords: Asphaltene-resin-paraffin deposits, Tank, Depressant additives, ARPD solvents.

\section{INTRODUCTION}

The petroleum extracted from Kazakhstan fields is mainly characterized by a high content of paraffin hydrocarbons, which is one of the factors for asphalt-resin-paraffin deposits (ARPD) formation ${ }^{1,2}$. Intensive formation of ARPD on the inner surface of oilfield and refinery equipment, especially in cold period of year, significantly reduces pumping units efficiency, impairs the throughput of oil pipelines and shortens the turnaround time of equipment operation ${ }^{3,4}$.

The problem of combating complications arising from the ARPD formation is especially important in the operation of refinery tank farms. Sediments accumulation makes it difficult to inspect the tanks condition, significantly reduces the effective capacity, which leads to process complication of their operation, to difficulty in quantitative and qualitative oil accounting, to decreasing in the technical and economic performance of oil reservoirs ${ }^{5}$. ARPD are dark brown or black, heavy-bodied, viscous mass of high viscosity, and consists of three main compounds groups: paraffin-naphthenic or paraffinnaphthene-aromatic hydrocarbons of $30-95 \%$ by weight, resins including heavy aromatics, $5-30 \%$ by weight, asphaltene $0.5-70 \%$ by weight.

This is an Open Access article licensed under a Creative Commons license: Attribution 4.0 International (CC- BY). Published by Oriental Scientific Publishing Company @ 2018

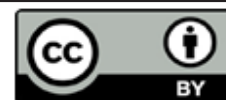


ARPD are also containing oils, sulfur, metals, mechanical impurities and water. Deposits composition may vary depending on petroleum composition and thermodynamic conditions under which the deposits are formed ${ }^{6-8}$. At the present time, dealing methods with ARPD provide working in two areas: prevention of deposits loss and deposits removal. Using of chemical methods based on dosing of chemical compounds in production, reducing and sometimes completely preventing deposits formation is the most promising method of combating ARPD ${ }^{13-16}$. An inhibition degree of ARPD formation in the use of reagents ranges from $50 \%$ to $95 \%$, while the main condition for high efficiency of the method is correct reagent selection and its dosage depending on deposits composition ${ }^{4}$.

Various methods are used to remove ARPD, which are divided into the main groups: mechanical (scrapers, scrapers-centralizers), thermal (washing with hot petroleum or water, sharp steam, electric furnaces, induction heaters), chemical (solvents and removers) ${ }^{9-12,14,18}$. Removal chemical methods for ARPD using hydrocarbon solvents are considered effective. However, significant disadvantages of the method are the high cost of solvents and economic costs aimed at storing and disposing of used solvents ${ }^{17,18}$. It is economically more advantageous to use heated petroleum with an addition of additives as a solvent, since the presence of a large amount of petroleum in each refinery and its return after the dissolution of the sediments does not entail technological schemes changes. An implementing cost of method can be divided into one-time (organization of small dosing stations) and permanent (the purchase of additives and heating petroleum). Carrying out works on deposits erosion in the summer significantly reduces economic and energy costs, by reducing additives concentration and heat necessary for heating petroleum.

The work purpose is a comprehensive evaluation of different additives effect on the dissolving properties of crude petroleum and the possibility of its use as a deposits solvent.

\section{MATERIALS AND METHODS}

To carry out the research, petroleum sample from the tank farm of the Kazakhstan oil refinery and a bottom sediment sample from the oil storage tank were selected. As chemical reagents that inhibit and remove ARPD, additives were tested: DP2G, DMN 1005 sample 1, DMN 1005 sample 2, NHT-I, PAO 80072 and PAO 82004.

Group composition of bottom sediments was determined by adsorption method according to Marcuson, while mechanical impurities content was determined in accordance with GOST 6370-83. Chromatographic determination of paraffins in oil and bottom sediments was carried out on an Auto System LX gas chromatograph, Perkin-Elmer model 3012 SIMDIS according to ASTM D2887.

Determination of the asphalt-resinous paraffin deposits (ARPD) inhibition degree was carried out by "cold rod" ("coldfinger") method in a special installation simulating the process of deposition of ARPD in the tank.

Solvent efficiency and removal capacity of petroleum was determined in accordance with the standard No ST-07.1-00-00-04 "Procedure for performing laboratory and experimental testing of chemical reagents for use in oil and gas production and treatment". As a solvent, petroleum with or without additives was used in the temperature range of $20-60^{\circ} \mathrm{C}$. The technique is developed on the basis of STP 03-153-2001, designed to evaluate solvent reagents effectiveness for destruction and removal of ARPD and consists of two independent methods:

- method $A$ is designed to determine the dissolving and destroying capacity of the solvent deposits that have not undergone heat treatment;

- method B is designed to determine solvent ability to keep in suspension the high molecular weight compounds that are part of the ARPD.

\section{RESULTS AND DISCUSSION}

The results of sediment samples analysis (Table 1) showed that the ratio of paraffin hydrocarbons to asphaltenes $\beta=P / R+A$ (paraffin/resin+ asphaltene), taking into account mechanical impurities can be classified as paraffin type, subgroup P1 in accordance with the accepted qualifications of ARPD ${ }^{19}$. 
Table 1: Sediment sample composition from oil storage tanks

\begin{tabular}{lccccc}
\hline Sample & $\begin{array}{c}\text { Paraffinic hydrocarbons } \\
\text { content, } \%\end{array}$ & Content of CA,\% & $\begin{array}{c}\text { Asphaltenes } \\
\text { content, } \%\end{array}$ & $\begin{array}{c}\text { The content of mech } \\
\text { impurities, } \%\end{array}$ & P/R+A ratio \\
\hline ARPD sample & 34.69 & 10.42 & 6.57 & 0.18 & 3.32 \\
\hline
\end{tabular}

An inhibitory activity of depressant additives evaluation showed that the inhibition degree compared to the ARPD that falls out of petroleum without heat treatment can be $52-60 \%$ (Table 2). That is, the input depressant additives can significantly improve the aggregative stability of the petroleum dispersion to thereby reduce loss ARPD during storage in the tank farm.

Table 2: Comparative data on petroleum inhibition degree depending on the treating method

\begin{tabular}{lc}
\hline Petroleum treatment method & Degree of inhibition, \% \\
\hline Crude without additives & - \\
TO $60^{\circ} \mathrm{C}$ & 28.8 \\
DP2G & 57.0 \\
DMN 1005 sample 1 & 55.6 \\
NHT-I & 52.4 \\
DMN 1005 sample 2 & 50.4 \\
PAO 80072 & 60.8 \\
PAO 82004 & 59.6 \\
\hline
\end{tabular}

Investigation results of ARPD solubility in petroleum at different temperatures are given in Table 3. As petroleum temperature rises, the degree of ARPD dissolution is significantly increases.

Table 3: Effectiveness of ARPD dissolution in oil at various temperatures

\begin{tabular}{ccccccccc}
\hline $\begin{array}{c}\text { Petroleum } \\
\text { temperature, } \\
{ }^{\circ} \mathrm{C}\end{array}$ & 30 & 60 & 120 & 180 & 240 & 300 & 360 \\
\hline 20.0 & inalterably & 0.7 & 2.7 & 2.5 & 2.8 & 4.1 & 6.1 \\
30.0 & inalterably & 0.6 & 6.0 & 8.4 & 12.1 & 15.2 & 18.3 \\
40.0 & inalterably & 14.4 & 24.4 & 29.3 & 34.7 & 40.2 & 46.6 \\
50.0 & inalterably & 34.0 & 52.4 & 65.6 & 70.0 & 75.2 & 81.3 \\
60.0 & inalterably & 57.9 & 100.0 & - & - & - & - \\
\hline
\end{tabular}

For describing the kinetics processes Erofeeva-Kolmogorov's equation were used:

$\alpha=1-\exp \left(-k \tau^{n}\right)$

Where $\alpha-$ is the ARPD dissolution efficiency in oil; $k$ - is a constant that determines the process rate constant; $\mathrm{n}-$ is a constant that determines the process nature; $\tau-$ is the time.
Coefficient $n$ value determines the process nature: for $n<1$, the process is diffusive; for $n>1$ - the kinetic process; $n=1$ - the rate of convective diffusion is comparable with the rate of molecular diffusion. To calculate the coefficient $n$, it is necessary to present the obtained data in the logarithmic dependence according to Fig. 1. The inclination angle slope to the abscissa axis gives the coefficient $n$.

To $20^{\circ} \mathrm{C}$ and $30^{\circ} \mathrm{C}$ coefficient value $\mathrm{n}$ greater than 1, respectively, at low temperatures the process rate is controlled by chemical dissolution. At temperatures above $40^{\circ} \mathrm{C}$, the value of $n$ is less than 1 , and the process is controlled by the rate of removal of the dissolved ARPD part from the surface.

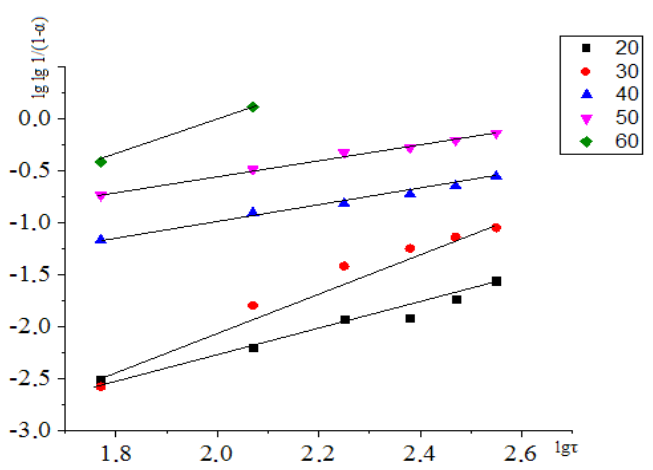

Fig. 1. Dependence of ARPD dissolution degree on time at different temperatures

According to the results of Method $B$ determination effectiveness (Table 4), it was established that complete ARPD dissolution is achieved only at $60^{\circ} \mathrm{C}$, at temperatures from $30^{\circ} \mathrm{C}$ and below the total ARPD dissolution, it is most likely not to occur at all, at temperatures from $40-50^{\circ} \mathrm{C}$ for the total ARPD dissolution too much volumes of petroleum needed, which in practice is inappropriate.

In accordance with Fig. 2, when extrapolating the plot of dissolution efficiency versus the volume of added petroleum at $50^{\circ} \mathrm{C}, 185 \mathrm{ml}$ of petroleum should be added to achieve complete dissolution, which means that the oil capacity at $50^{\circ} \mathrm{C}$ is 9.04 $\mathrm{kg} / \mathrm{m}^{3}$. The same index at $60^{\circ} \mathrm{C}$ is $23.15 \mathrm{~kg} / \mathrm{m}^{3}$. 
Table 4: Efficiency of ARPD dissolution in oil at various temperatures and oil volumes

\begin{tabular}{ccccccccc}
\hline $\begin{array}{c}\text { Petroleum } \\
\text { temperature, } \\
{ }^{\circ} \mathrm{C}\end{array}$ & $30 / 28$ & $60 / 42$ & $90 / 56$ & $120 / 70$ & $150 / 84$ & $180 / 98$ & $210 / 112$ & $240 / 126$ \\
\hline 30.0 & 0.1 & 0.3 & 3.6 & 5.5 & 7.3 & 9.0 & 9.7 & - \\
40.0 & 3.9 & 14.5 & 21.3 & 29.8 & 33.3 & 36.0 & 37.9 & 42.5 \\
50.0 & 21.4 & 67.6 & 80.2 & 82.6 & 83.4 & 85.7 & 86.6 & 88.0 \\
60.0 & 50.4 & 84.5 & 100.0 & - & - & - & - & - \\
\hline
\end{tabular}

The obtained results make it possible to conclude that at the remaining $20 \%$ of hardly soluble precipitate substances with the highest melting point are at $50^{\circ} \mathrm{C}$, and the number of petroleum components capable of dissolving them chemically is small. At $60^{\circ} \mathrm{C}$, the hardly soluble precipitate obviously melts and homogenizes.

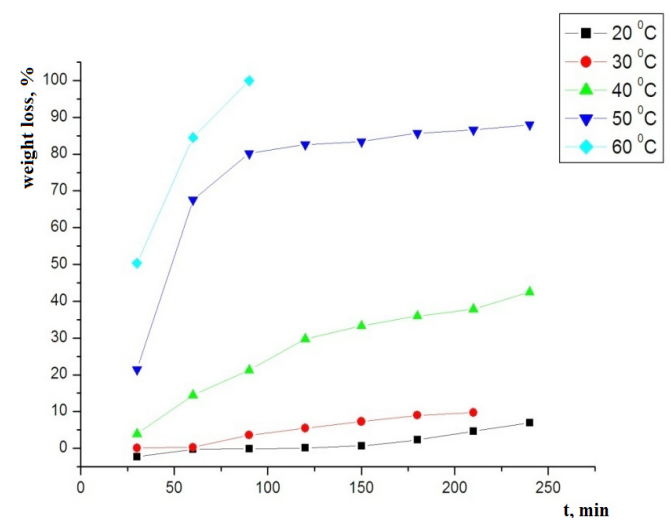

Fig. 2. ARPD dissolution effectiveness in petroleum at various temperatures

ARPD solubility investigations in the presence of additives (Table 5) showed that at low temperatures the petroleum solubility is minor, but at $60^{\circ} \mathrm{C}$ the ARPD dissolution occurs after the first hour and all additives show a comparable result. At $50^{\circ} \mathrm{C}, 100 \%$ solubility was shown by PAO80072 and DMN 1005 sample 2.

The investigation results of the additives effect on petroleum capacity with respect to ARPD are given in Table 6 . The best results were obtained for DMN additives sample 2 and DP2G, petroleum capacity was $33.11 \mathrm{~kg} / \mathrm{m}^{3}$ and $36.58 \mathrm{~kg} /$ $\mathrm{m}^{3}$, respectively, with petroleum without additives provides a capacity gain on $43.02 \%$ and $58.01 \%$. Other additives did not show a gain in capacity.

Research work results of selected chemical reagents dispersing properties showed that the best dispersant effect with respect to the analyzed ARPD sample is the additive PAO 80072. In accordance with applied procedure, it is assigned an "excellent" rating, in which in the flask treated with this additive with formation water and a sample ARPD, after thermostating at a temperature of $60^{\circ} \mathrm{C}$, uniform particles of $0.5-1.0 \mathrm{~mm}$ in size remained, the settling particles time was no more than 3 minutes, the flask walls were clean (Figure 3 a).

Additive NHT-I is inferior in the PAO 80072 effectiveness, its dispersant properties evaluation is "good" (Fig. 3 b). A satisfactory dispersant effect was shown by the DMN-1005 additive sample 1; when used, the ARPD particles are inhomogeneous up to $5 \mathrm{~mm}$ in size, the settling time is not more than $3 \mathrm{~min}$ the flask walls are contaminated to $50 \%$ of the working surface (Figure $3 \mathrm{c}$ ).

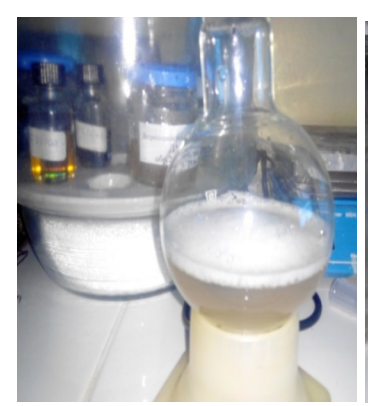

(a)

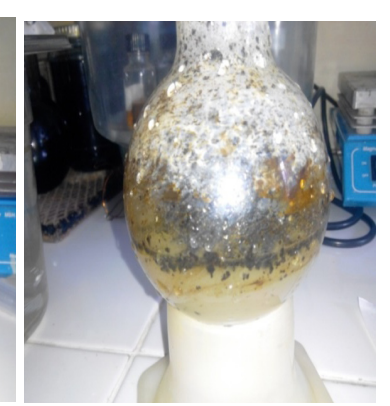

(b)

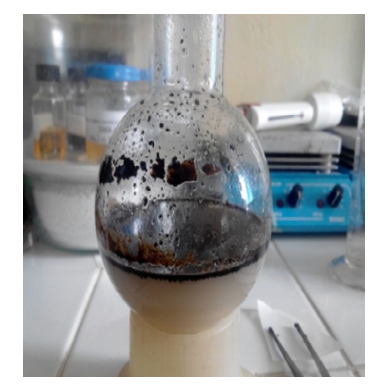

(c)

Fig. 3. Demonstration of the additives action: a) PAO 80072; B) NHT-I; C) DMN-1005 sample 1 
Table 5: ARPD dissolution effectiveness in petroleum at various temperatures in the presence of additives

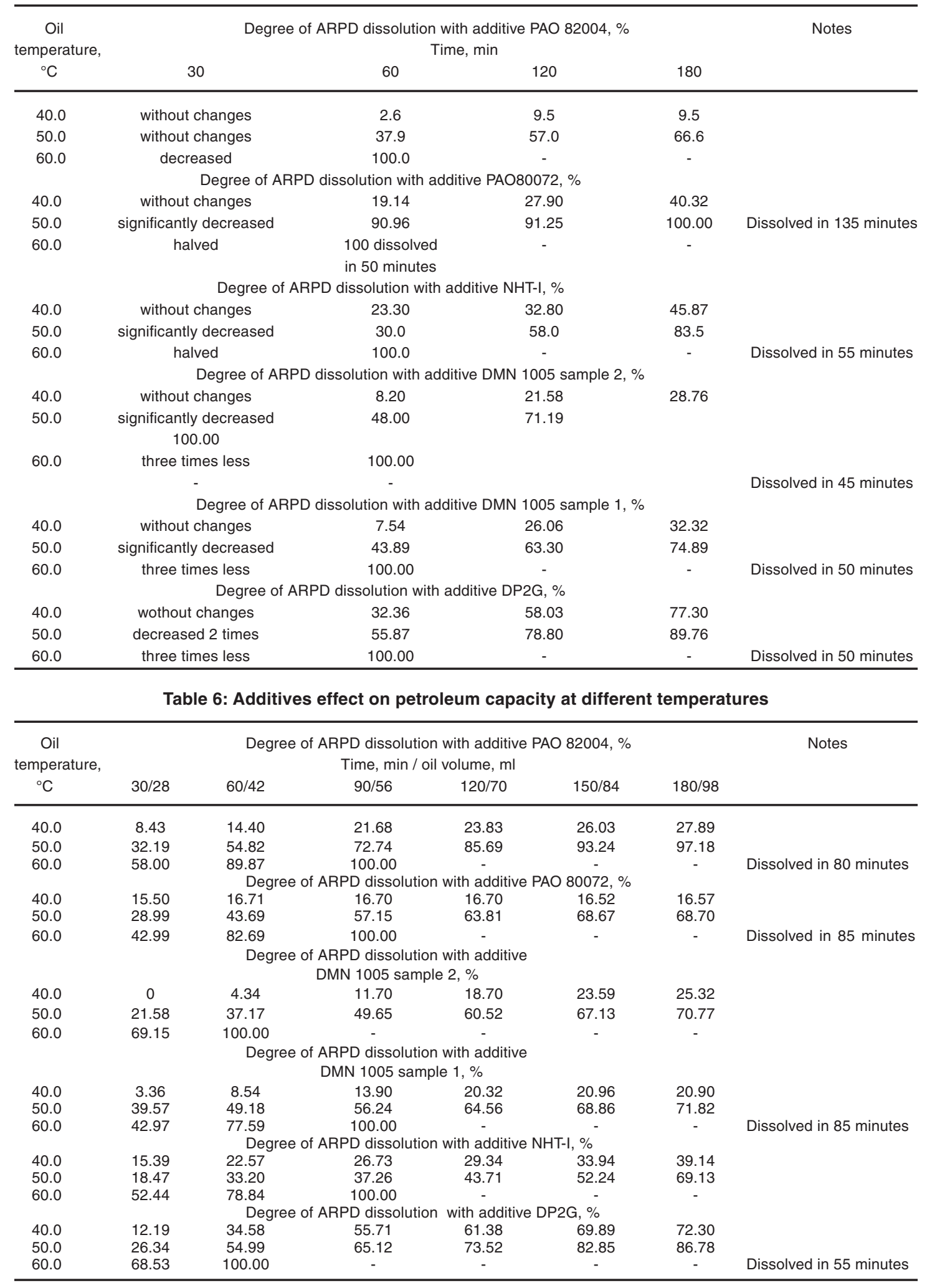


Based on research results, an additives effectiveness in relation to ARPD (Table 7) was evaluated according to the following four criteria:

1) ARPD inhibition efficiency, scores were set: 1 place - 6, 2 - 5, etc. up to 1 ;

2) An effectiveness of additive action in ARPD dissolution, scores were set: 1 place - 6, 2 - 5, etc. up to 1 ;

3) The effect on petroleum capacity as a solvent, scores were set: 1 place - 6, 2 - 5, etc. to 1 ;

4) The additive dispersant effect, scores were set in accordance with evaluation: excellent - 4, good - 3 , satisfactory - 2 , unsatisfactory -1 .

Table 7: Results of above-referred criteria assessment

\begin{tabular}{lccccc}
\hline Additive & Criterion 1 & Criterion 2 & Criterion 3 & Criterion 4 & Total \\
\hline DP2G & 4 & 3 & 6 & 1 & 14 \\
PAO 80072 & 6 & 6 & 2 & 4 & 18 \\
PAO 82004 & 5 & 1 & 4 & 1 & 11 \\
DMN 1005 sample 1 & 3 & 2 & 1 & 2 & 8 \\
DMN-1005 sample 2 & 1 & 5 & 5 & 1 & 12 \\
NHT-I & 2 & 3 & 3 & 3 & 11 \\
\hline
\end{tabular}

Thus, the best results were obtained with the use of additives PAO 80072, DP2G and $D M N-1005$ sample 2. DP2G additive usage is impossible due to lack of industrial production. The choice between PAO 80072 additives and DMN-1005 sample 2 should be determined after integrated tests production in conditions close to the factory ones.

Petroleum capacity determination will show a more reliable result in additives presence only when switching to large volumes, since in the laboratory scale the differences are leveled.

In general, the use of additives has a positive effect, both on the low-temperature petroleum characteristics and on its dissolving effect on ARPD. However, despite the increase in the petroleum capacity as a solvent, it cannot be classed as good solvents, which have a capacity about $200 \mathrm{~kg} / \mathrm{m}^{3}$. But taking into account the expenses amount for necessary solvents quantity, the arrangements for their placement, subsequent disposal, and the use of petroleum with additives as an ARPD solvent is cost-effective.

\section{CONCLUSION}

Research work results showed that depressant additives injection significantly improves an aggregative stability of oil dispersion system for given petroleum, thereby reducing the loss of ARPD during storage in tank farm. It has been established that in additives presence, ARPD dissolution time is reduced by half. At $50^{\circ} \mathrm{C}, 100 \%$ solubility showed PAO80072 and, respectively, DMN sample 2 at 135 and 180 minutes.

Carried out investigations of additives effect on petroleum capacity in relation to ARPD determined the best results with the use of DMN additives sample 2 and DP2G. Petroleum capacity for them at the same time was $33.11 \mathrm{~kg} / \mathrm{m}^{3}$ and $36.58 \mathrm{~kg} / \mathrm{m}^{3}$, respectively, which in comparison with oil without additives provides a capacity increase of $43.02 \%$ and $58.01 \%$. The best result was obtained using PAO 80072 additives and DP2G. The choice between them should be determined after integrated tests production in conditions close to the factory ones.

\section{ACKNOWLEDGEMENT}

This research was carried out within the framework of the project No 0220/ Program-target financing-15-MES "Development of new catalysts and non-waste technology of complex processing of hydrocarbon raw materials for the production of high quality motor fuels" due to scientific projects financing under the of the Scientific Committee of the Ministry of Education and Science of the Republic of Kazakhstan. 


\section{REFERENCES}

1. Bakirova, S.F.; Buyanova, N.S.; Makhanova, M.B. Oil and Gas Technologies., 2001, 1, 65-68.

2. Vasil'yanova, L.S. Oil and Gas Technologies., 2006, 2, 83-90.

3. Ibragimov, N.G.; Khafizov, A.R.; Shaydakov, V.V. Monograph Complications in oil production., 2003, 1-302.

4. Ivanova, L.V.; Burov, E.A.; Koshelev, V.N. J. Oil and Gas Business., 2011, 1, 268-280.

5. Kononov, O.V. Abstract disser. Ufa, Russia. 2001., 1-21.

6. Sadykov, A.N.; Nigmatullina, R.Sh.; Fazlyev, D.F.; Farrahova, F.R.; Shakyrzyanov, R.G. Sci. works Problems of Chemistry of Petroleum., 1992, 302-305.

7. Sharifullin, A.V.;Baibecova, L.R.; Khamidullin, R.F. J. Oil and Gas Technologies., 2006, 4, 34-41.

8. Thanh, N.X.; Hsieh, M.; Philp, R.P. Organic Geochem., 1999, 30, 119-132.

9. Baymukhametov, M.K.; Dolmatov, M.Yu.; Rogachev, M.K. Sci. Conf. IV Congress of Russian oil and gas producers., 2003, 78.
10. Nasyrov, A. M. Vniioeng., 1991, 1-44.

11. Rogachev, M. K.; Stryzhnev, K. V. LLC NedraBusiness Center., 2006, 295, 55.

12. Ngia, T.; Veliyev, M.M.; Dung, L.V. Sci.conf. Energy Efficiency., 2013, 99-102.

13. Petrov, N.A.; Nogayev, N.A.; Davydova, I.N.; Komleva, S.F. J. Oil and Gas Business., 2007, 1, 1-10.

14. Khokhlov, N.G.; Vagapov, R.R.; Shagitov, Z.M.; Mustafin, A.S. Oil Industry., 2006, 1, 110-111.

15. Waild, J. J. Oil and Gas Technologies., 2009, 9, 25-29.

16. Hashmi, S.M.; Firoozabadi, A. J. Colloid and Interface Science., 2013, 394, 115-123.

17. Markhasin, V.I.; Peshkin, O.V.; Zlotsky, S.S. DAN., 1984, 1, 145.

18. Glushenko, V.N.; Silin, N.N. Oilfield Chemistry., 2009, 1-475.

19. Ibragimov, G.Z.; Sorokin, V.A.; Khisamutdinov, N.I. Chemical reagents for oil production: a Handbook. 1986, 1-240. 